\title{
Research on central sensitization of endometriosis-associated pain: a systematic review of the literature
}

This article was published in the following Dove Press journal:

Journal of Pain Research

\section{Ping Zheng* \\ Wen Zhang* \\ Jinhua Leng \\ Jinghe Lang}

Department of Obstetrics and Gynecology, Peking Union Medical College Hospital, Chinese Academy of Medical Science and Peking Union Medical College, Beijing, People's Republic of China

*These authors contributed equally to this work
Correspondence: Jinghe Lang; Jinhua Leng Department of Obstetrics and Gynecology, Peking Union Medical College Hospital, Chinese Academy of Medical Science and Peking Union Medical College, $I^{\text {st }}$

Shuaifuyuan, Dongcheng District, Beijing 100730, People's Republic of China

Tel +86 I36 9332 8258; +86 I37 $0 \mid 2986 I 6$ Email langjh@hotmail.com;

lengjenny@vip.sina.com

\begin{abstract}
Endometriosis-associated pain afflicts an enormous number of women who suffer from endometriosis. There is an urgent need to explore the pathogenesis of endometriosisassociated pain to identify targets for treatment of hyperalgesia. A search was conducted in PubMed, Web of Science, Embase, and the Cochrane Library using the search terms "endometriosis" AND ("pain" OR "hyperalgesia" OR "nociception" OR “allodynia”) AND "central sensitization". The search was limited to articles published in English from 01/01/ 2008 to the present. Among the search results, 15 articles were eligible for systematic review, including 6 reviews, 6 human studies (one in the form of a conference abstract only), and 3 animal studies. The articles were classified into 4 lists to describe the mechanism of endometriosis-associated pain and synthesize different aspects of research on it. In conclusion, there is a need to explore the mechanism of endometriosis-associated pain in terms of innervation, vascularization, local inflammation, cross-correlated visceral sensitization, and central sensitization to identify the target molecules and signaling pathways of key genes and relevant biomarkers through new techniques, all with the goal of developing a more comprehensive treatment strategy for endometriosis than is currently available.
\end{abstract}

Keywords: endometriosis-associated pain, neurogenic inflammation, mechanism, central sensitization

\section{Introduction}

Endometriosis, a condition in which lesions made of endometrium form ectopically outside the uterus, is a common gynecological disease in reproductive-age women. One in ten women has been diagnosed with this type of lesion. Recently, several common effect of endometriosis, including pain (found in $80 \%$ of patients), infertility $(60 \%)$ and/or pelvic mass $(40 \%),{ }^{1}$ have been classified as a syndrome. Studies have indicated that women with endometriosis-associated pain manifest several symptoms: chronic pelvic pain (CPP), dysmenorrhea, dyspareunia, and dyschezia. Additionally, substantial burdens can arise from associated nociceptive conditions such as viscerovisceral hyperalgesia syndrome, painful bladder syndrome (formerly called interstitial cystitis) and irritable bowel syndrome. ${ }^{2}$

The diagnosis of endometriosis depends on laparoscopy, in which the cyst or nodule can be seen directly in the peritoneal cavity. Laparoscopy is also the most effective way to eliminate the ectopic lesion. However, most patients still suffer from persistent pain after surgery. Some women with this disease can relieve pain 
via oral acyeterion, gonadotropin-releasing hormone agonist (GnRH-a), or nonsteroidal anti-inflammatory drugs. ${ }^{3}$ However, there remains a potential problem because clinically significant results require prolonged and repeated administration, which causes side effects in a large number of patients. Therefore, an imperative need exists for alternative, more mechanism-based treatments to ease the extreme hyperalgesic symptoms of endometriosis.

A growing body of evidence attests that patients with endometriosis endure pain associated with abnormal angiogenesis and the growth of novel nerve fibers in close proximity to ectopic lesions. Endometriotic lesions create an inflammatory environment and change the quality or quantity of inflammatory mediators or neurotransmitters, thereby stimulating peripheral nerve sensitization by remodeling the structure of peripheral synapses and accelerating conduction along nerve fibers. Berkely and McAllister ${ }^{4-6}$ discovered that ectopic cysts harvested from rat models with established endometriosis and from human patients develop their own C-fiber (sensory afferent) and sympathetic (autonomic efferent) nerve supply. The supply is rooted in nerve fibers innervating sites near the lesions; these fibers sprout branches into the growths. In 2003, Bajaj $^{7}$ and his team proposed that central sensitization may be involved mechanistically in the development and maintenance of endometriosis-related pain. Those researchers hypothesized that persistent nociceptive input from endometriotic tissues might result in increased responsiveness among dorsal horn neurons processing input from the affected viscera and somatic tissues. Their subsequent study found a reduced pain threshold but improvement in the reaction to pricking and in mechanical hyperalgesia in 10 patients with laparoscopically confirmed endometriosis who suffered from pelvic pain. Spisak, ${ }^{8}$ by evoking blood-oxygen-level-dependent (BOLD) responses in a block-design functional magnetic resonance imaging (fMRI) experiment, identified that central sensitization to chronic pain can be observed as altered connectivity in key regions of the nociceptive network. An increasing number of studies focus on the relationship between differences in gene expression and the central sensitization mechanism of endometriosis-associated pain.

This review was organized with the aim of systematically synthesizing the literature published to date regarding the central sensitization mechanism of endometriosis-associated pain. The goal of this undertaking is to unearth the underlying pathogenesis and provide reliable evidence to aid the search for novel methods of nonhormone target therapy for endometriosis-associated pain.

\section{Methods}

\section{Literature search}

Articles and review papers retrieved from the databases PubMed, Web of Science, Embase, and the Cochrane Library. Gray literature was excluded. The following search terms were used: "endometriosis" AND ("pain" OR "hyperalgesia" OR "nociception" OR "allodynia") AND "central sensitization". The search was limited to articles published in English from 01/01/2008 to the present.

\section{Data selection}

All studies identified by the searches were screened for inclusion. If our inclusion criteria were not all addressed in the abstract, then the methods section of the paper was screened. The inclusion criteria were as follows: (1) women or animals as the study subjects; and (2) women with endometriosis accompanied by pain, or animals with induced endometriosis-like lesions and hyperalgesia. The types of study designs included for review were randomized controlled trials (RCTs), cohort studies, crosssectional studies, observational studies and reviews. Articles in languages other than English were excluded. Some potentially useful papers were excluded from the present meta-analysis because their data were too heterogeneous. The abstracts were double-checked by at least two authors to determine whether the reports fit the inclusion criteria for this study (Figure 1).

\section{Data extraction}

The articles found in the search were classified into the categories of reviews, research articles and conference presentations; furthermore, the research articles were subdivided into human research and animal research. For data collection and analysis, two authors independently extracted key data from the selected studies into several data tables according to the above classification. The tables contained general information such as author name, year of publication, locations and other characteristics (study characteristics, eligibility criteria, interventions, outcome measurements, etc.). All included articles were stored in EndNote software to assist the reviewers in managing data and to enable a third author to eliminate 


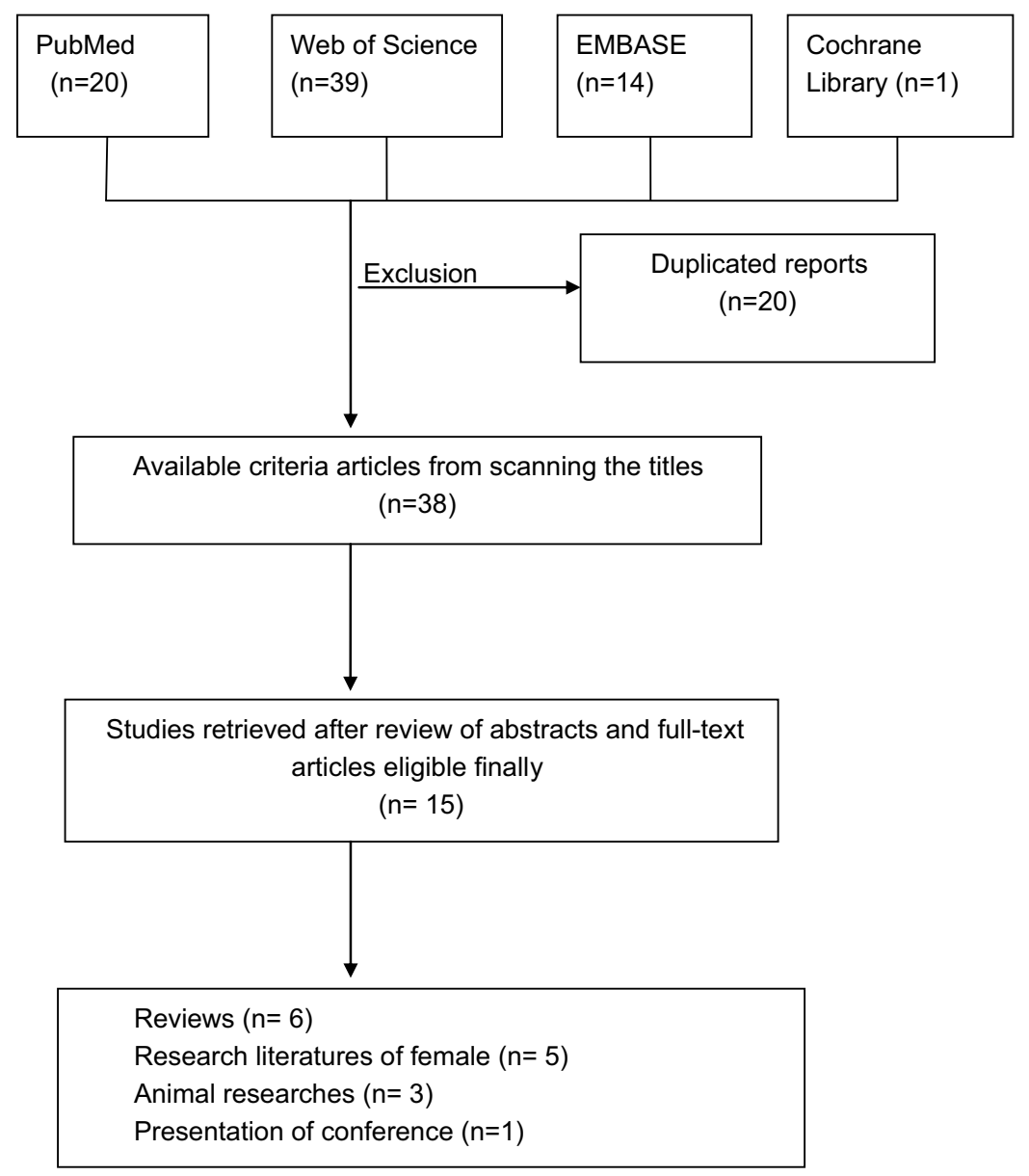

Figure I Flow chart of selection processes for eligible studies.

duplicate publications. All disagreements regarding study inclusion or data extraction were resolved by another author.

\section{Results}

Seventy-four publications were identified from PubMed, Web of Science, Embase and the Cochrane Library using the specified search terms. Twenty duplicates were removed from the list of search results, and the remaining studies were screened for inclusion and exclusion criteria by reading the abstracts and full texts. Ultimately, 15 articles were eligible for systematic review, including 6 reviews, 6 human studies (one of which was in the form of a conference abstract only), and 3 animal studies .

The 15 articles were classified into 4 categories in order to describe and synthesize information from similar study types. The human studies are summarized in Table 1; the animal studies are presented Table 2; the reviews are analyzed in Table 3 , and the conference presentations are explained individually in Table 4.

\section{Discussion}

In recent years, studies on endometriosis-related pain have focused on CPP in women of reproductive age, but most patients with endometriosis have also shown some specific allodynia, such as abdominal myofascial pain syndrome, ${ }^{24}$ visceral cross-organ nociception and muscle fascial pain; ${ }^{25,26}$ therefore, in recent years, these ambiguous pain locations have become a research hotspot for endometriosis-related pain. Most of the researchers have reviewed some original research articles accumulated over years the years, involving case-control, prospective, retrospective, randomized controlled and nonrandomized controlled study designs. Generally, pain patients who were diagnosed laparoscopically with endometriosis were assigned to an experimental group, while pain patients without endometriosis were classified in a control group, and pain assessment was performed with a visual analogue scale (VAS) scoring system. The pain patients received an intervention, such as medication (oral or intravenous) or acupuncture, sometimes accompanied by adjuvant 


\begin{tabular}{|c|c|c|c|c|c|c|}
\hline 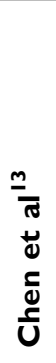 & 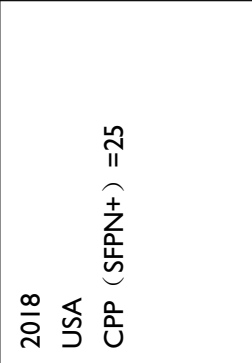 & 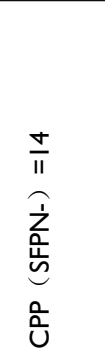 & 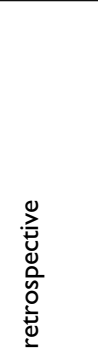 & 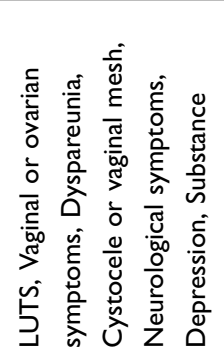 & 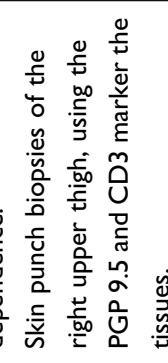 & 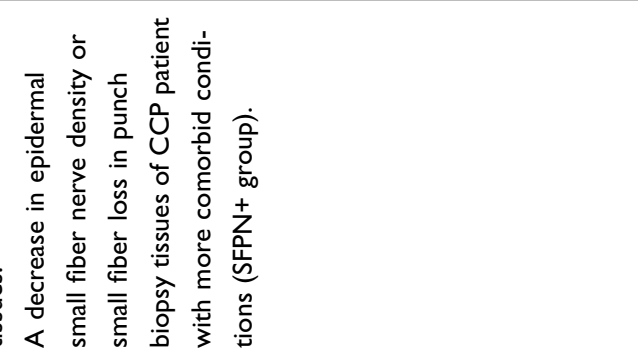 \\
\hline $\begin{array}{l}\frac{\pi}{\pi} \\
\stackrel{0}{0} \\
\stackrel{0}{I}\end{array}$ & 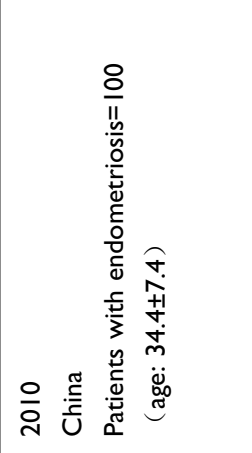 & 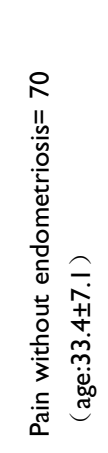 & 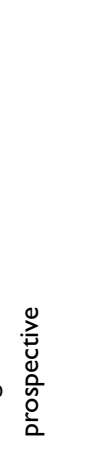 & 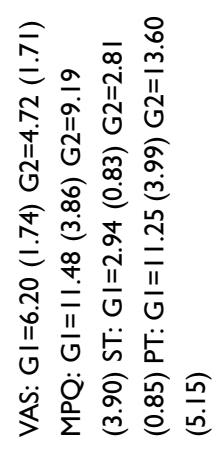 & 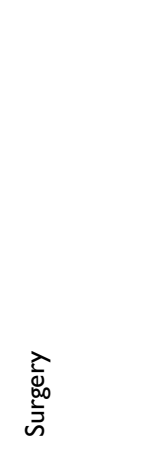 & 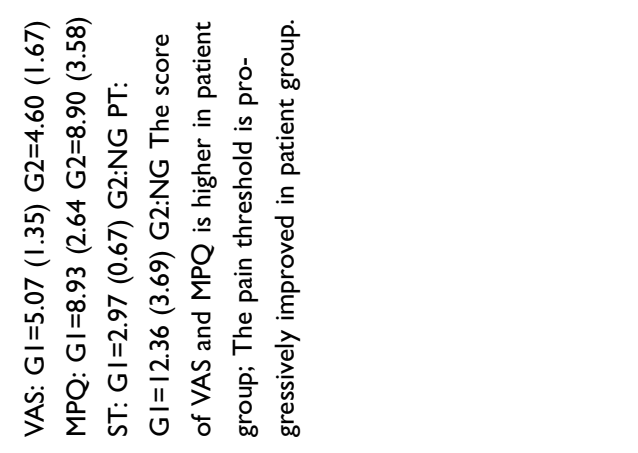 \\
\hline 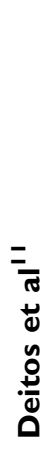 & 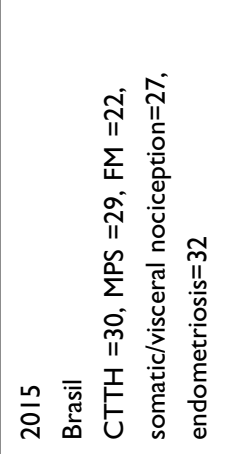 & 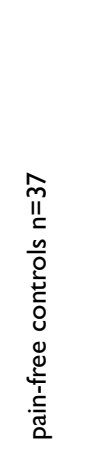 & $\begin{array}{l}0 \\
\stackrel{0}{\grave{U}} \\
\stackrel{0}{0} \\
\stackrel{0}{0}\end{array}$ & 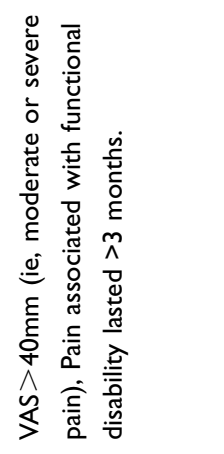 & 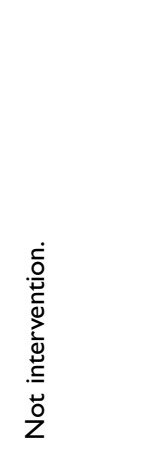 & 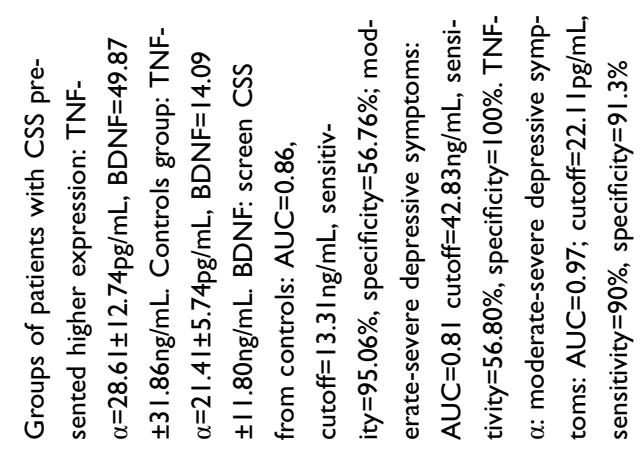 \\
\hline 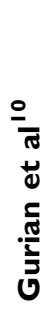 & 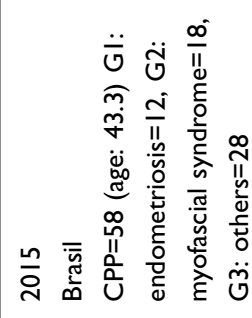 & 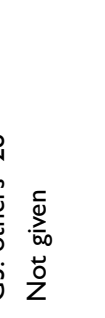 & 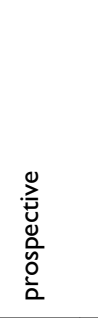 & 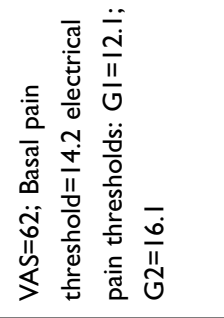 & 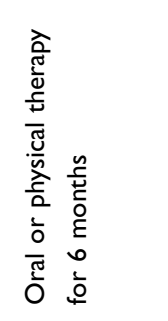 & 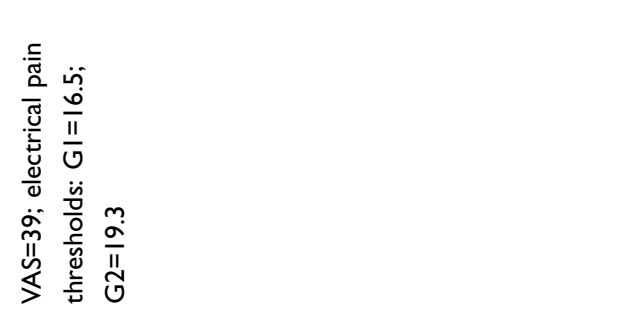 \\
\hline 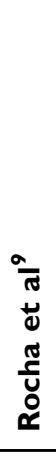 & 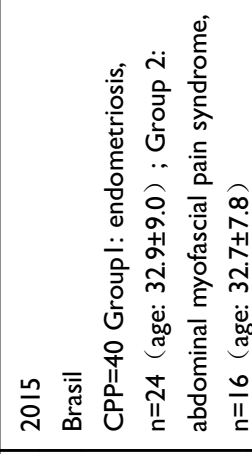 & 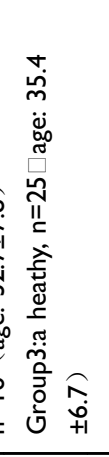 & 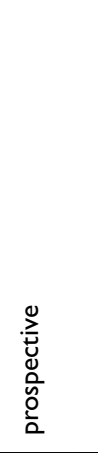 & 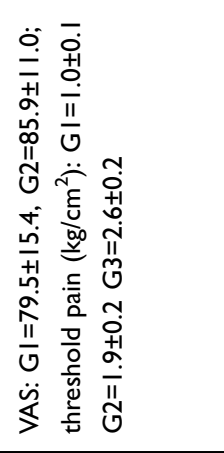 & 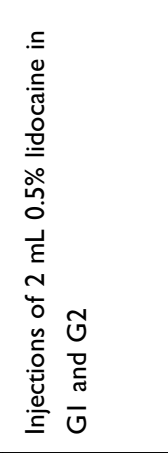 & 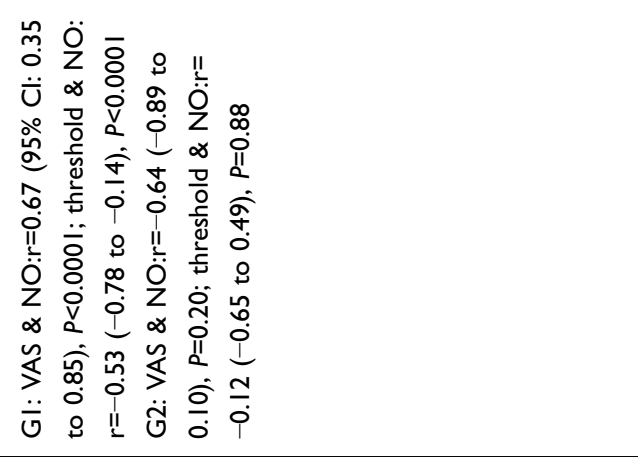 \\
\hline 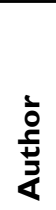 & 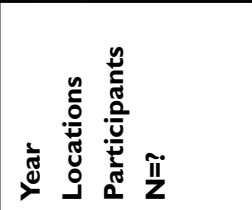 & $\begin{array}{l}\frac{\pi}{z} \\
\frac{\pi}{0} \\
0 \\
0 \\
0\end{array}$ & 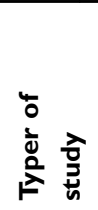 & 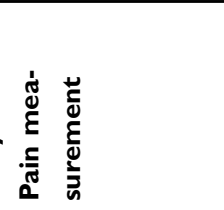 & 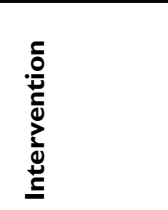 & 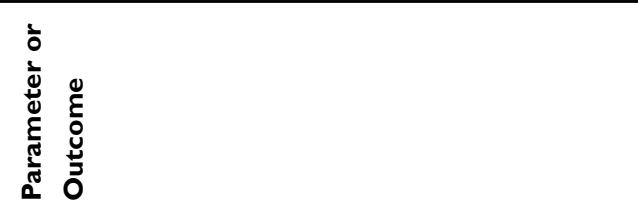 \\
\hline
\end{tabular}




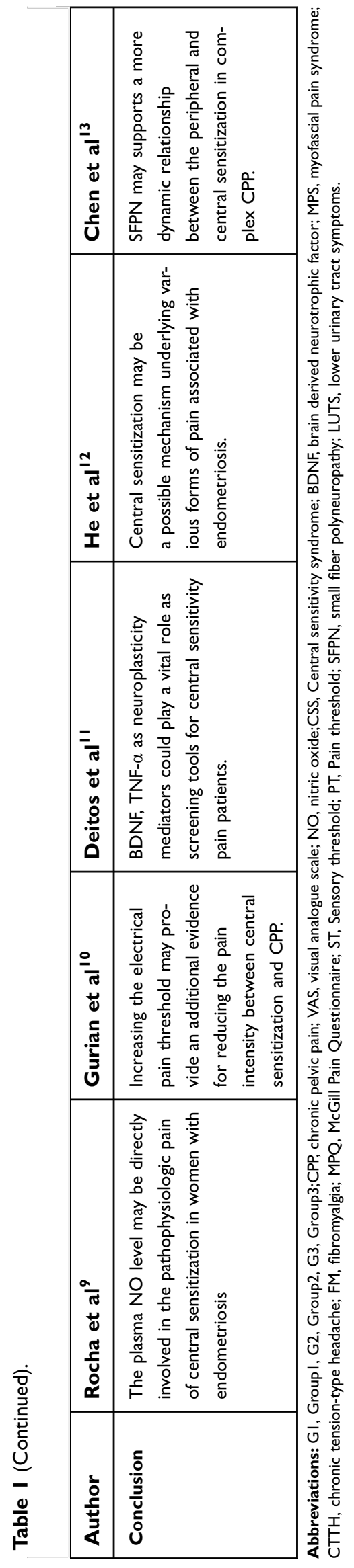

therapy; subsequently, the effectiveness of the treatment was evaluated using a pain scale, such as the VAS, Iowa Pain Thermometer (IPT) or McGill Pain Questionnaire (MPQ), ${ }^{9}$ or a protein biomarker, such as BDNF, TNF- $\alpha$, or the PEGylated form of a specific protein. ${ }^{11,27}$ Some studies have found that although the pain was relieved after the experimental treatment measures, it recurred after a few months; this phenomenon is related to the central sensitization mechanism of endometriosis. ${ }^{23,28-30}$ Nagabukuro $^{31}$ has confirmed that endometriotic pelvic lesions contain abnormal neurovascular proliferation. These phenomena may be caused by abnormalities in conduction after peripheral sensitization, leading to central neurological abnormalities in the phenomenon known as central sensitization. The five articles cited above are the most comprehensive studies on the central sensitization mechanism of pain in endometriosis. Their subject populations were mainly from Brazil, China and the United States. This geographical scope is relatively limited and not representative of the entire world. Consequently, the results of the analysis are applicable only to the region, and the quality of evidence needs to be improved.

In three studies of animal models of the central sensitization mechanism of endometriosis-associated pain, pain intensity was evaluated in mice by behavioral experiments, for instance, the hot plate test, von Frey filaments, and the open field test, with or without drug intervention. Subsequently, the brains of the mice were dissected in search of target proteins or genes in candidate regions via staining and sequencing. $\mathrm{Li}$ and Greaves ${ }^{14,15}$ found changes in functional regions of the genome through sequencing of candidate regions, and they also detected abnormal expression of some genes as a result of central sensitization. Vicuna et $\mathrm{al}^{32}$ identified that the expression of Serpina3n and Lct were downregulated in the insula of endometriotic mice, which may play a vital role in central sensitization to endometriosis-associated pain of central sensitization. Hence, they assumed that an intervention against central sensitization would relieve the symptoms of pain by altering these abnormally regulated genes. This hypothesis, however, is based on animal experiments and is not mature enough for clinical application. There is insufficient evidence to conclude that patients with endometriosis-related pain have genetic changes similar to those in animal models; therefore, this conclusion cannot be extended to humans at present. However, preclinical animal exploration provides an experimental basis for future clinical research. 
Table 2 Animal studies for selected studies

\begin{tabular}{|c|c|c|c|}
\hline Author & Li et al $^{14}$ & Greaves et $\mathrm{al}^{15}$ & Dodds $^{16}$ \\
\hline Year & 2018 & 2017 & 2018 \\
\hline Location & USA & UK & Australia \\
\hline Species & Female C57BL/6 mice & Female C57BL/6 mice & Female C57BL/6 mice \\
\hline ENDO, $\mathrm{N}=$ ? & 12 & 18 & $\begin{array}{l}5 \text { (endometrial fragments from } 5 \\
\text { donor mice were injected into abdo- } \\
\text { men cavity) }\end{array}$ \\
\hline Control, $\mathbf{N}=$ ? & Sham $=12$ & $\begin{array}{l}\mathrm{OVX}+\mathrm{E} 2=6 \square \mathrm{OVX}+\mathrm{E} 2+\mathrm{PBS}=6 \\
\text { Sham }=6\end{array}$ & $\begin{array}{l}6 \text { (sterile saline were injected into } \\
\text { abdomen cavity) }\end{array}$ \\
\hline Pain measurement & $\begin{array}{l}\text { Hot plate test/Open field test/Tail } \\
\text { suspension test }\end{array}$ & $\begin{array}{l}\text { Open field test/abdominally directed } \\
\text { licking/Von frey test }\end{array}$ & No measurement \\
\hline Intervention & $x^{2}$ & $\begin{array}{l}\text { Injection the inhibitor of TRPVI, JNJ } \\
\text { I72032I2, EP4 antagonist L-I6I982, } \\
\text { the EP2 antagonist TG6-I0-I and EP2 } \\
\text { antagonist (PF-044I8948) in all } \\
\text { groups. }\end{array}$ & $\begin{array}{l}\text { ENDO: endometrial fragments from } \\
5 \text { donor mice were injected into } \\
\text { abdomen cavity. Control: sterile saline } \\
\text { were injected into abdomen cavity. }\end{array}$ \\
\hline $\begin{array}{l}\text { Parameter or } \\
\text { Outcome }\end{array}$ & $\begin{array}{l}\text { - Altered CNS electrophysiology: } \\
\text { pain, anxiety, and depression result } \\
\text { from impairment in GABAergic and } \\
\text { glutamatergic transmission onto } \\
\text { neurons in the amygdale. } \\
\text { - Differentially expressed genes in the } \\
\text { brains: upregulated(Gpr88, Glra3 in } \\
\text { insula; Chrnb4, Npas4 in the hippo- } \\
\text { campus; Lcn2 in the amygdala); } \\
\text { downregulated(Lct, Serpina3n in } \\
\text { insula; Nptx2 in amygdala). }\end{array}$ & $\begin{array}{l}\text { - EP2, EP4, COX-I, COX-2, PGE2, } \\
\text { increased in endometriosis lesions. } \\
\text { - EP2, Cox-I, ScnIla and TrpvI } \\
\text { mRNA concentrations were } \\
\text { increased in DRG. } \\
\text { - The EP2 antagonism could reverse } \\
\text { both peripheral and secondary } \\
\text { hyperalgesia. }\end{array}$ & $\begin{array}{l}\text { - Astrocytic GFAP and microglial } \\
\text { CDIIb were highly expressed in } \\
\text { immunoreactions of Spinal cords } \\
\text { (TI3-SI) as endometriosis-like } \\
\text { lesions. }\end{array}$ \\
\hline Conclusion & $\begin{array}{l}\text { Gene abnomal expression in brain } \\
\text { result from the mechanism of central } \\
\text { sensitization, which provide evidence } \\
\text { for molecular targets to cure pain. }\end{array}$ & $\begin{array}{l}\text { EP2 receptor antagonism could be } \\
\text { a key target for the potential thera- } \\
\text { pies of endometriosis-associated pain. }\end{array}$ & $\begin{array}{l}\text { Endometriosis-like lesions resulted in } \\
\text { the adaptations in nonneuronal, } \\
\text { immune-like cells of the central ner- } \\
\text { vous system to modulate central } \\
\text { sensitization and pain. }\end{array}$ \\
\hline
\end{tabular}

Abbreviations: EMS, induced- endometriosis by surgery; Sham, Sham surgeries for controls; OVX, ovariectomised; COX-I, cyclooxygenase-I; COX-2, cyclooxygenase-2; DRG, dorsal root ganglia; GFAP, glial fibrillary acidic protein.

Endometriosis-related pain is currently considered a form of neuropathic or neuroinflammatory pain. A large number of experimental studies, both human and animal, have demonstrated that abnormal microscopic neurogenesis and angiogenesis occur in ectopic lesions, supporting the development, density, infiltration and even metastasis of ectopic endometrium. ${ }^{4,17,20,33}$ The perception of pain is caused by this abnormal proliferation of nerve fibers and vessels. Inflammatory factors are released into the sensory afferent nerve at the distal end of the lesion by noxious stimuli, and the nociceptive signal is transferred to the nerve root of the dorsal horn of the spinal cord. After simple handling, the pain signal is transferred to the thalamus, the brain stem, and finally the cerebral cortex. ${ }^{34}$ If the lesion sites are stimulated persistently by those abnormal factors, the transmission of pain signals will change, magnifying future pain and forming more intense memories of pain in the cerebral cortex. During the process of signal transduction, the function of the corresponding immune cells and cytokines changes accordingly, promoting the enhancement and amplification of the pain signals to some extent. ${ }^{35}$ As-Sanie $^{36}$ and his colleagues determined that women with endometriosis-associated CPP shown increased levels of combined glutamine and glutamate (Glx) within the anterior insula and increased anterior insula connectivity to the medial prefrontal cortex (mPFC), which may play a role in the pathophysiology of CPP independent of the presence of endometriosis. Of course, the degree of pain is positively correlated with the density of nerves at the lesion. The higher the density of nerve fibers, the more pronounced the pain. Reviews by $\mathrm{Liu}^{37}$ and 
Table 3 Reviews for selected studies

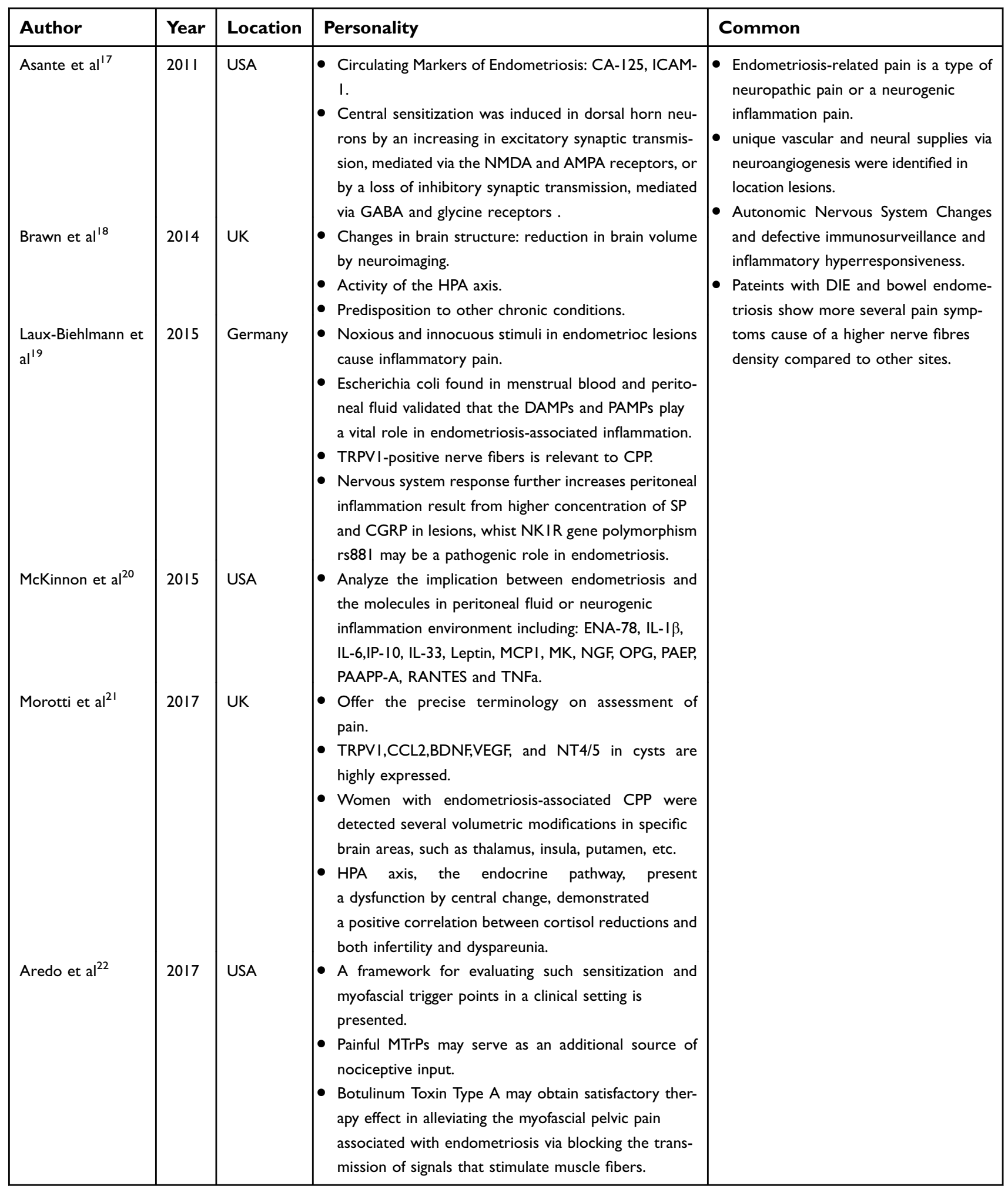

Abbreviations: CA-125, cancer antigen-I25 or carbohydrate antigen-125; ICAM-I, serum-soluble intercellular adhesion molecule-I; CPP, chronic pelvic pain; HPA, Hypothalamic-Pituitary-Adrenal; NMDA, glutamate N-methyl-D-aspartate; AMPA, $\alpha$-amino3-hydroxy-5-methyl-4-isoxazole-propionate; GABA, $\gamma$-aminobutyric acid; DAMPs, damage-associated molecular patterns; PAMPs, pathogen-associated molecular patterns; TRPVI, transient receptor potential vanilloid I; SP, neuropeptide substance P; CGRP, calcitonin gene-related peptide; NKIR, neurokinin I receptor, is one of the SP receptor; DIE, deep infiltrating endometriosis. 
Table 4 the presentation at conference

\begin{tabular}{|l|l|l|l|l|l|l|}
\hline Author & Year & Location & Hypothesis & Methods & Results & Conclusions \\
\hline Guo et al $^{23}$ & 2009 & China & $\begin{array}{l}\text { women with } \\
\text { endometriosis } \\
\text { have increased } \\
\text { pain perception as } \\
\text { compared with } \\
\text { women without. }\end{array}$ & $\begin{array}{l}\text { VDS,VAS and IPT (VAS and } \\
\text { MPQ scores) assess the } \\
\text { their severity of dysmenor- } \\
\text { rheal between endometrio- } \\
\text { sis and without } \\
\text { endometriosis. }\end{array}$ & $\begin{array}{l}\text { Women with endo- } \\
\text { metriosis had } \\
\text { a significantly higher } \\
\text { VAS and MPQ } \\
\text { scores than without } \\
\text { endometriosis. }\end{array}$ & $\begin{array}{l}\text { Central sensitization may well } \\
\text { be a possible mechanism for } \\
\text { ciated with endometriosis, } \\
\text { may underlie both pathologi- } \\
\text { cal and adaptive functions in } \\
\text { the affected visceral areas. }\end{array}$ \\
\hline
\end{tabular}

Abbreviations: VDS, verbal descriptor scale; VAS, visual analogue scale; IPT, ischemic pain test; MPQ, McGill Pain Questionnaire.

Serrano ${ }^{38}$ hold that deep infiltrating endometriosis (DIE) and ectopic growths on the intestinal wall have greater neurological density than ectopic lesions in other parts, meaning that this type of patient will have more severe pain.

The exploration of biomarkers has played an important part in research efforts to characterize the mechanism of endometriosis pain. CA125 has been widely used in the detection of endometriosis, but no study, to our knowledge, demonstrates clearly that the increase in CA125 is positively correlated with the degree of pain. Existing research merely indicates that the amount of CA125 in patients with endometriosis is elevated, which can serve as supplemental diagnostic sign. ${ }^{17,39}$ Some studies also suggest that ICAM-1 is associated with the degree of pain in endometriosis. ${ }^{17} \mathrm{~A}$ review by Brawn ${ }^{18}$ states that chronic, repeated local pain stimuli affect the normal activity of the hypothalamic-pituitaryadrenal (HPA) axis and may then exacerbate pain through a reduction in cortisol levels. Meanwhile, the structure of specific brain areas is changed, such as the periaqueductal gray (PAG), a vital region in the descending pain modulatory pathways, ${ }^{40}$ the volume of the PAG is increased in women with emdometriosis pain compared to those without pain, as observed by seedbased resting functional connectivity magnetic resonance imaging (fcMRI). Laux-Biehlmann ${ }^{19}$ summarized the important role that damage-associated molecular patterns (DAMPs) and pathogen-associated molecular patterns (PAMPs) play in pain signaling from ectopic lesions. At the same time, it is also recognized that TRPV1, substance $P(\mathrm{SP})$ and calcitonin gene-related peptide (CGRP) show high expression in lesions and nearby sites that are subject to pelvic pain. On a related note, the NK1R gene polymorphism rs881 may play an important role in this process, providing a new possibility for pain treatment targets, but further verification is needed. From the review of McKinnon, ${ }^{20}$ it is not difficult to see that many other inflammatory factors such as Leptin, MCP1, MK, NGF, OPG, PAEP, PAAPP-A, RANTES and TNF- $\alpha$ are relevant to the pain associated with endometriosis, which merits further attention in the field of inflammatory pain. Morotti's view is similar to that of Brawn and further proposes that volumetric changes in the thalamus, insula and putamen result from long-tern endometriosis-related pain. ${ }^{21}$ Aredo $^{22}$ took another perspective to explain endometriosis-related pain at sites such as myofascial trigger points (MTrPs); he noted that botulinum toxin type A can alleviate myofascial pain by blocking signal transmission.

A study presented by Guo et $\mathrm{al}^{23}$ also used questionnaires to evaluate the symptoms of CPP in patients. The investigators conducted a brief analysis of the underlying cause of intractable endometriosis-associated pain driven by central sensitization.

In summary, we can conclude that endometriosisassociated pain is closely related to central sensitization, as validated in both animal experiments and human case-control studies. Attention should be focused on the molecular pathways of pain signaling, with the intention of identifying the target-molecule signaling pathways of key genes and relevant biomarkers through new techniques, blocking the transmission of amplified signals by effective methods, and blocking or reversing the results of central sensitization from neurotoxic stimulation in order to relieve pain and improve quality of life in patients suffering from endometriosis-associated pain.

\section{Acknowledgment}

This study was supported by grant from the National Natural Science Foundation of China (81471440). 


\section{Disclosure}

The authors report no conflicts of interest in this work.

\section{References}

1. Falcone T, Flyckt R. Clinical management of endometriosis. Obstet Gynecol. 2018;131(3):557-571. doi:10.1097/AOG.0000000000002469

2. Mirkin D, Murphy-Barron C, Iwasaki K. Actuarial analysis of private payer administrative claims data for women with endometriosis. J Manag Care Pharm. 2007;13(3):262-272. doi:10.18553/ jmcp.2007.13.3.262

3. Erny R, Guidicelli B. Treatment of pain in endometriosis. Contrib Gynecol Obstet. 1987;16:205-211.

4. Zhang G, Dmitrieva N, Liu Y, McGinty KA, Berkley KJ. Endometriosis as a neurovascular condition: estrous variations in innervation, vascularization, and growth factor content of ectopic endometrial cysts in the rat. Am J Physiol Regul Integr Comp Physiol. 2008;294(1):R162-71. doi:10.1152/ajpregu.00649.2007

5. McAllister SL, McGinty KA, Resuehr D, Berkley KJ. Endometriosisinduced vaginal hyperalgesia in the rat: role of the ectopic growths and their innervation. Pain. 2009;147(1-3):255-264. doi:10.1016/j. pain.2009.09.022

6. McAllister SL, Dmitrieva N, Berkley KJ, Esteban FJ. Sprouted innervation into uterine transplants contributes to the development of hyperalgesia in a rat model of endometriosis. PLoS One. 2012;7 (2):e31758. doi:10.1371/journal.pone.0031758

7. Bajaj P, Bajaj P, Madsen H, Arendt-Nielsen L. Endometriosis is associated with central sensitization: a psychophysical controlled study. J Pain. 2003;4(7):372-380.

8. Spisak T, Pozsgay Z, Aranyi C, et al. Central sensitization-related changes of effective and functional connectivity in the rat inflammatory trigeminal pain model. Neuroscience. 2017;344:133-147. doi:10.1016/j.neuroscience.2016.12.018

9. Rocha MG, Gomes VA, Tanus-Santos JE, et al. Reduction of blood nitric oxide levels is associated with clinical improvement of the chronic pelvic pain related to endometriosis. Braz J Med Biol Res. 2015;48(4):363-369. doi:10.1590/1414-431X20143619

10. Gurian MBF, Neto OBP, Silva J, et al. Reduction of pain sensitivity is associated with the response to treatment in women with chronic pelvic pain. Pain Med. 2015;16(5):849-854. doi:10.1111/pme.12625

11. Deitos A, Dussan-Sarria JA, de Souza A, et al. Clinical value of serum neuroplasticity mediators in identifying the central sensitivity syndrome in patients with chronic pain with and without structural pathology. Clin J Pain. 2015;31(11):959-967. doi:10.1097/ AJP.0000000000000194

12. He WW, Liu XS, Zhang YQ, Guo S-W. Generalized hyperalgesia in women with endometriosis and its resolution following a successful surgery. Reprod Sci. 2010;17(12):1099-1111. doi:10.1177/ 1933719110381927

13. Chen A, De E, Argoff C. Small fiber polyneuropathy is prevalent in patients experiencing complex chronic pelvic pain. Pain Med. 2018;20(3):521-527. doi:10.1038/nn.3844

14. Li T, Mamillapalli R, Ding S, et al. Endometriosis alters brain electro-physiology, gene expression and increased pain sensitization, anxiety, and depression in female mice. Biol Reprod. 2018;99 (2):349-359. doi:10.1093/biolre/ioy035

15. Greaves E, Horne AW, Jerina H, et al. EP2 receptor antagonism reduces peripheral and central hyperalgesia in a preclinical mouse model of endometriosis. Sci Rep. 2017;7:44169. doi:10.1038/ srep44169

16. Dodds KN, Beckett EAH, Evans SF, et al. Spinal glial adaptations occur in a minimally invasive mouse model of endometriosis: potential implications for lesion etiology and persistent pelvic pain. Reprod Sci. 2019;26(3):357-369. 1933719118773405.
17. Asante A, Taylor RN. Endometriosis: the role of neuroangiogenesis. Annu Rev Physiol. 2011;73:163-182. doi:10.1146/annurev-physiol $-012110-142158$

18. Brawn J, Morotti M, Zondervan KT, Becker CM, Vincent K. Central changes associated with chronic pelvic pain and endometriosis. Hum Reprod Update. 2014;20(5):737-747. doi:10.1093/humupd/dmu025

19. Laux-Biehlmann A, d'Hooghe T, Zollner TM. Menstruation pulls the trigger for inflammation and pain in endometriosis. Trends Pharmacol Sci. 2015;36(5):270-276. doi:10.1016/j. tips.2015.03.004

20. McKinnon BD, Bertschi D, Bersinger NA, Mueller MD. Inflammation and nerve fiber interaction in endometriotic pain. Trends Endocrinol Metab. 2015;26(1):1-10. doi:10.1016/j. tem.2014.10.003

21. Morotti M, Vincent K, Becker CM. Mechanisms of pain in endometriosis. Eur $J$ Obstetrics Gynecology Reprod Biol. 2017;209:8-13. doi:10.1016/j.ejogrb.2016.07.497

22. Aredo JV, Heyrana KJ, Karp BI, Shah JP, Stratton P. Relating chronic pelvic pain and endometriosis to signs of sensitization and myofascial pain and dysfunction. Semin Reprod Med. 2017;35(1):88-97. doi: $10.1055 / \mathrm{s}-0036-1597123$

23. Guo S, He W, Liu X. Evidence for central sensitization in women with endometriosis. Int $J$ Gynecology Obstetrics. 2009;107:S196S197. doi:10.1016/S0020-7292(09)60739-6

24. Karp B, Tandon H, Sinaii N, et al. Widespread myofascial dysfunction and regional sensitization in women with endometriosis-associated chronic pelvic pain. Neurology. 2018;90 (15). doi:10.1212/WNL.0000000000005560

25. Costantini R, Affaitati G, Wesselmann U, Czakanski P, Giamberardino MA. Visceral pain as a triggering factor for fibromyalgia symptoms in comorbid patients. Pain. 2017;158 (10):1925-1937. doi:10.1097/j.pain.0000000000000992

26. Amasyali SY, Diracoglu D. Pathophysiology of myofascial pain syndrome: the latest opinions. Nobel Medicus. 2014;10(2):5-11.

27. Mueller MD, Imboden S, Nirgianakis K, et al. Endometriosis and pelvic pain: relationship between nerves and inflammation. J Endometriosis Pelvic Pain Disord. 2015;7:S11.

28. Hoffman D. Central and peripheral pain generators in women with chronic pelvic pain: patient centered assessment and treatment. Curr Rheumatol Rev. 2015;11(2):146-166.

29. Guo SW. The pain of endometriosis-associated pains. J Endometriosis. 2012;4(3):132.

30. Experimental pain tolerance is decreased and independent of clinical pain intensity in patients with endometriosis.

31. Nagabukuro H, Berkley KJ. Influence of endometriosis on visceromotor and cardiovascular responses induced by vaginal distention in the rat. Pain. 2007;132(Suppl 1):S96-103. doi:10.1016/j. pain.2007.04.039

32. Vicuna L, Strochlic DE, Latremoliere A, et al. The serine protease inhibitor SerpinA3N attenuates neuropathic pain by inhibiting $\mathrm{T}$ cell-derived leukocyte elastase. Nat Med. 2015;21(5):518-523. doi: $10.1038 / \mathrm{nm} .3852$

33. Coxon L, Horne AW, Vincent K. Pathophysiology of endometriosis-associated pain: a review of pelvic and central nervous system mechanisms. Best Pract Res Clin Obstet Gynaecol. 2018;51:53-67. doi:10.1016/j.bpobgyn.2018.01.014

34. Wang Y, Zhang M, Xie F, et al. Upregulation of alpha(2)delta-1 calcium channel subunit in the spinal cord contributes to pelvic organ cross-sensitization in a rat model of experimentally-induced endometriosis. Neurochem Res. 2015;40(6):1267-1273. doi:10.1007/ s11064-015-1592-3

35. Paul Dmowski W, Braun DP. Immunology of endometriosis. Best Pract Res Clin Obstet Gynaecol. 2004;18(2):245-263. doi:10.1016/j. bpobgyn.2004.02.001 
36. As-Sanie S, Kim J, Schmidt-Wilcke T, et al. Functional connectivity is associated with altered brain chemistry in women with endometriosis-associated chronic pelvic pain. J Pain. 2016;17 (1):1-13. doi:10.1016/j.jpain.2015.09.008

37. Liu SJ, Lv W. A laparoscopic surgery for deep infiltrating endometriosis and the review of literature. Clin Exp Obstet Gynecol. 2016;43(4):616-618.

38. Serrano JS, Stauffer JA. Ectopic pancreas in the wall of the small intestine. J Gastrointest Surg. 2016;20(7):1407-1408. doi:10.1007/ s11605-016-3104-4
39. Cheng YM, Wang ST, Chou CY. Serum CA-125 in preoperative patients at high risk for endometriosis. Obstet Gynecol. 2002;99(3):375-380.

40. Eippert F, Tracey I, Chen A, De E, Argoff C. Pain and the PAG: learning from painful mistakes. Nat Neurosci. 2014;17(11):1438-1439. doi: $10.1038 / \mathrm{nn} .3844$

\section{Publish your work in this journal}

The Journal of Pain Research is an international, peer reviewed, open access, online journal that welcomes laboratory and clinical findings in the fields of pain research and the prevention and management of pain. Original research, reviews, symposium reports, hypothesis formation and commentaries are all considered for publication. The manuscript management system is completely online and includes a very quick and fair peer-review system, which is all easy to use. Visit http:// www.dovepress.com/testimonials.php to read real quotes from published authors. 